\title{
Cardiac Toxicity after Radiotherapy for Breast Cancer: Myths and Facts
}

\author{
Mirko Nitsche ${ }^{a}, b \quad$ René Pahl $^{b}$ Karen Huber ${ }^{b}$ Kirsten Eilf ${ }^{b}$ Juergen Dunst ${ }^{b}$ \\ ${ }^{a}$ Zentrum für Strahlentherapie und Radioonkologie, Bremen/Westerstede, Germany;

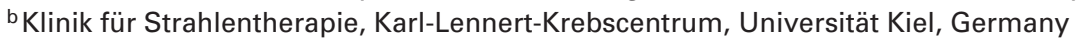

\section{Keywords \\ Breast cancer · Cardiotoxicity · Radiotherapy}

\section{Summary}

Radiotherapy is an important component in the multidisciplinary treatment of breast cancer. In recent years, the cardiac risks of radiation have been discussed several times. This problem has long been known and resolved from the radiotherapeutic point of view. The current data is briefly described here.

\section{Introduction}

It is well known since the first meta-analysis by Cuzick and colleagues [1] from the 1980s (incidentally one of the first meta-analysis in medicine at all) that postoperative radiation therapy in breast cancer may have adverse effects in long-term survivors. Even then, an increased mortality was observed in long-term survivors.

In studies that were started after 1982 [2], these adverse effects of radiotherapy have not been observed anymore (table 1). The positive effects of radiotherapy therefore came more into play. With increasing follow-up, the weight of these recent studies in the meta-analyses has grown. This is surely one of the reasons why the survival benefit of radiotherapy has become increasingly apparent $[3,4]$. On the basis of Scandinavian studies and cancer registries, a higher rate of cardiac deaths could be identified as the cause for increased long-term mortality. This was significant only in patients with left-sided breast cancer. Therefore, the radiation exposure of the heart was suspected as the cause. Detailed studies primarily from Scandinavia were able to demonstrate a clear dose-response relationship. This dose effect was already detected in the 2005 meta-analysis of the Early Breast Cancer Trialists' Collaborative Group (EBCTCG) [3] (table 2). Since then, these consolidated findings have been consistently taken into account for modern radiotherapy treatment planning [5]. The analysis recently published in the New England Journal of Medicine is merely an update of the above-cited data and confirms the facts known for years [6].

\section{Cardiotoxicity of Radiotherapy}

\section{Pathophysiology and Epidemiology}

Cardiotoxicity after radiation therapy is not new and was already described in detail in the 1970s; clinical research at that time focused on young patients with mantle irradiation for Hodgkin's disease. This treatment technique delivered high radiation doses to large proportions of the heart. Generally, pericarditis was observed as acute and late toxicity at that time, as well as congestive heart failure, ischemic coronary artery disease, arrhythmia, or myocardial infarction [7-9]. The leading cause of non-cancer mortality among long-term survivors after radiotherapy for Hodgkin's lymphoma was cardiovascular death [10]. It should be noted that radiation doses applied to the whole heart have been much higher than in the treatment of breast cancer, even in those times [11-13]. In Scandinavian breast cancer studies, mainly an increased incidence of ischemic events and unclear cardiac deaths was observed $[2,6]$.

The exact cause of cardiotoxicity after radiotherapy for breast cancer is not clear [14]. Based on the clinical data and animal experiments, various causes of radiogenic cardiac toxicity are discussed. Experimental evidence suggests indirect harmful effects of microvascular and macrovascular damage on the myocytes. It has been postulated that radiotherapy leads to an acute inflammation within the heart blood capillaries and to continuous inflammatory

\section{KARGER \\ Fax +497614520714

\section{() 2015 S. Karger GmbH, Freiburg}

$1661-3791 / 15 / 0102-0131 \$ 39.50 / 0$
Dr. Mirko Nitsche

Zentrum für Strahlentherapie und Radioonkologie

Gröpelinger Heerstr. 406-408

28239 Bremen, German

nitsche@strahlentherapie-bremen.com 
Table 1. Increased cardiac mortality only in old studies

Table 2. Data of the EBCTCG, evaluation 2005

\begin{tabular}{|c|c|c|c|c|}
\hline \multirow{2}{*}{$\begin{array}{l}\text { Patient } \\
\text { enrolment, } \\
\text { years }\end{array}$} & \multicolumn{4}{|c|}{ Increase in risk for cardiac death (hazard ratio) in follow-up } \\
\hline & Up to 10 years & $10-14$ years & $15-19$ years & $\geq 20$ years \\
\hline 1973-1982 & 1.19 & 1.35 & 1.64 & 1.90 \\
\hline 1983-1992 & 0.99 & 1.02 & 1.11 & 1.21 \\
\hline 1993-2002 & 0.97 & 0.99 & & no data \\
\hline 2003-2008 & 1.00 & no data & no data & no data \\
\hline
\end{tabular}

Irradiated patients had a higher rate of cardiac deaths compared to the control group without irradiation. When listing the studies in chronological order, this was only significant in studies that recruited until 1982 (significant risks are highlighted in the table in italics). In studies with recruitment from 1983 to 1992, a very small, not more significant risk resulted after more than 15 years. In subsequent work, increased cardiac mortality was no longer observed (modified from [2]).

\begin{tabular}{lllll}
\hline $\begin{array}{l}\text { Heart dose, } \\
\text { range (mean) }\end{array}$ & $\begin{array}{l}\text { Total number } \\
\text { of patients }\end{array}$ & $\begin{array}{l}\text { Cardiac events in } \\
\text { irradiated patients }\end{array}$ & $\begin{array}{l}\text { Cardiac events in non- } \\
\text { irradiated patients }\end{array}$ & $\begin{array}{l}\text { Hazard ratio } \\
\text { for annual risk }\end{array}$ \\
\hline $0-5$ Gy (3 Gy) & 9,982 & $2.9 \%$ & $2.4 \%$ & 1.08 (n.s.) \\
$5-15$ Gy (9 Gy) & 7,850 & $5.4 \%$ & $3.8 \%$ & 1.32 \\
$>15$ Gy (17 Gy) & 2,265 & $11.0 \%$ & $6.4 \%$ & 1.63 \\
\hline
\end{tabular}

Irradiated patients had a higher rate of cardiac deaths. In the low-dose group, this effect was not significant. In the group with higher radiation doses, cardiac events even increased in the control group without irradiation. This can be explained mainly by the fact that high doses of radiation were used in the earliest studies with long follow-up and thus higher cardiac risk became apparent in non-irradiated patients in the control group. As a consequence of the data, one should have an average heart dose of less than 3-5 Gy in modern technology. Under these conditions, there is no significant cardiac risk [3].

n.s. $=$ Not significant.

processes, resulting in endothelial cell proliferation and formation of fibrin thrombi with obstruction of the myocardial capillary lumen. Further on, this could lead to ischemia and myocardial cell death. Cardiac tissue is replaced by fibrotic tissue, as the myocytes have no ability to divide [15]. Subsidiary, radiation also induces an inflammatory process in the major arteries of the heart, leading to accelerated atherosclerosis. Endothelial cell damage and transmigration of monocytes into the intima lead to the ingestion of lipoproteins and the formation of fatty streaks [15]. Therefore, it is quite comprehensible that epidemiologic studies detected baseline cardiac risk factors as independent risk factor for cardiovascular disease after radiotherapy. Those risk factors are age, hypertension, diabetes mellitus, total cholesterol, family history of early myocardial infarction, and smoking [15]. In animal experiments, changes in the density of beta-receptors are observed at low doses of radiation to the heart. It has been suggested that the increased stimulation of the sympathetic nerve serves to compensate subclinical myocardial injury [16]. Perhaps, a combination of all factors described above plays a role. Several studies deal with the effect of dose on specific cardiac structures in patients undergoing radiotherapy. Lind et al. [17] evaluated post-radiation regional myocardial heart perfusion changes with single-photon emission tomography (SPECT) in 69 patients. They correlated left anterior descending artery (LAD) distribution SPECT changes with percent irradiated left ventricle (LV) volume and risk factors for coronary artery disease. Radiotherapy for left-sided breast cancer was associated with short-term SPECT defects in vascular distribution, corresponding to the radiation portals 6 months after radiotherapy. They did not find increases in SPECT defects in heart regions outside the tangential photon beams. Factors related to the extent of perfusion defects were the percent irradiated LV, hormonal treatment, and pre-radiotherapy hypercholesterolemia. None of the patients experienced clinically significant short-term cardiac events like myocardial infarction, but it clearly shows the impact of radiotherapy on microvascularization in the myocardium. There is currently no defined threshold dose for the LAD and the definition of the LAD as organ at risk is difficult in its reproducibility [18]. Pericardial effusion (PE) in the treatment of breast cancer is a very rare effect. Wei et al. [19] reported about PE in patients treated for esophageal cancer. The greatest risk was shown for patients with an irradiated heart volume of more than $46 \%$ with $30 \mathrm{~Gy}$, resulting in $73 \%$ PE. Those doses are by far not achieved in radiotherapy for breast cancer, so that the pericardium as organ at risk does not play a definite role in breast cancer radiotherapy. The same applies to the aortic bulb and the valvular plane. The incidence of valvular disease is only related to mediastinal radiation doses $>30 \mathrm{~Gy}$ and younger age at irradiation, which was shown for survivors of Hodgkin's disease. After 20 years of follow-up, Machann et al. [20] performed cardiac magnetic resonance imaging in 36 patients and revealed a hemodynamically relevant valvular dysfunction in 13 patients and a perfusion deficit in 21 patients. 


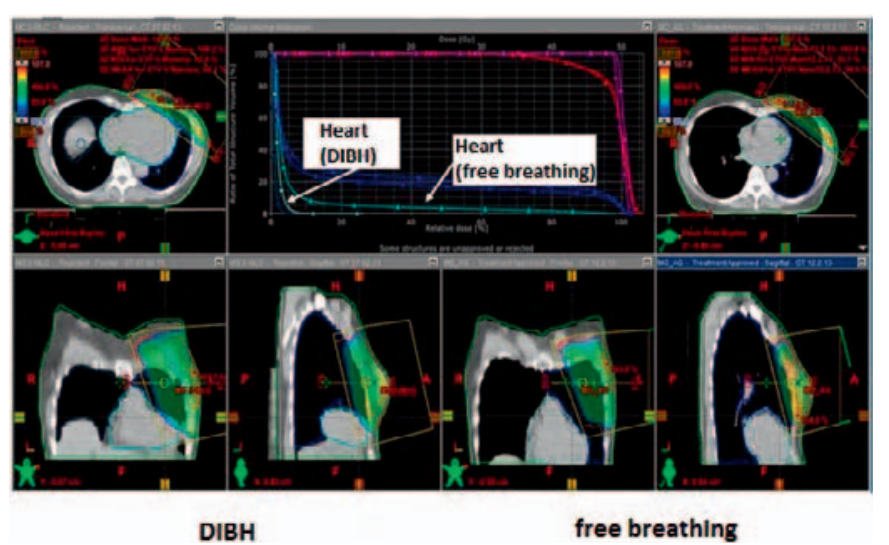

Fig. 1. Dose distribution in radiotherapy of the left breast during free breathing (left) and DIBH technique (right). The 3-dimensional dose distributions on corresponding CT sections (same height in the chest) show that the contours of the heart are different and the distance between the heart and the radiation field is greater for inspiration. This leads to a lower radiation dose to the heart, evident in the dose-volume histogram (top center). The median heart dose is almost identical, but the maximum dose is significantly reduced by the DIBH technique.

\section{Discussion}

The recently published analysis of Darby et al. [6] confirms well-known data on cardiac risks in ancient studies and has identified a dose-response relationship, but it gives no conclusive answer to the most important question of how best to protect the heart against radiation toxicity. The cardiac radiation doses in the metaanalysis are rough estimates of each individual patient because 3-dimensional treatment planning with calculation of cardiac doses (which is the contemporary standard) was not yet possible [21]. Furthermore, only mean heart doses were presented in the analyses. The authors of the New England Journal of Medicine article concluded that all exposure of the heart to radiation is associated with an increased risk. From the radiotherapeutic point of view, this conclusion is unsustainable after careful analysis of the presented data. It is most likely that there is a threshold dose, and probably a volume effect. Unfortunately, neither a critical volume nor a critical threshold dose can be exactly determined based on these historical studies. In studies with modern technology (as of 1990), no increased rate of cardiac risks was observed [2]. In recent prospective studies, in which the heart dose was calculated as part of the treatment planning, the mean heart doses are well below the dose of $3 \mathrm{~Gy}$, which is the threshold dose for a significant cardiac effect recently reported by Darby et al. [6]. As evidence for this low cardiac stress, we can refer to our recent multicenter ARO2010-01 study. An innovative fractionation schedule (hypofractionation with integrated boost) was tested, and doses to organs at risk were routinely determined and documented during treatment planning. The mean heart dose was only $1.48+0.9 \mathrm{~Gy}(\mathrm{n}=151)$ [22]. Analyzing the more common normofractionated standard adjuvant tangential radiotherapy in breast cancer, another one of our own recent treatment studies also proved low cardiac toxicity. We found a mean heart dose of 3.9 Gy (range 1.7-6.1 Gy, standard

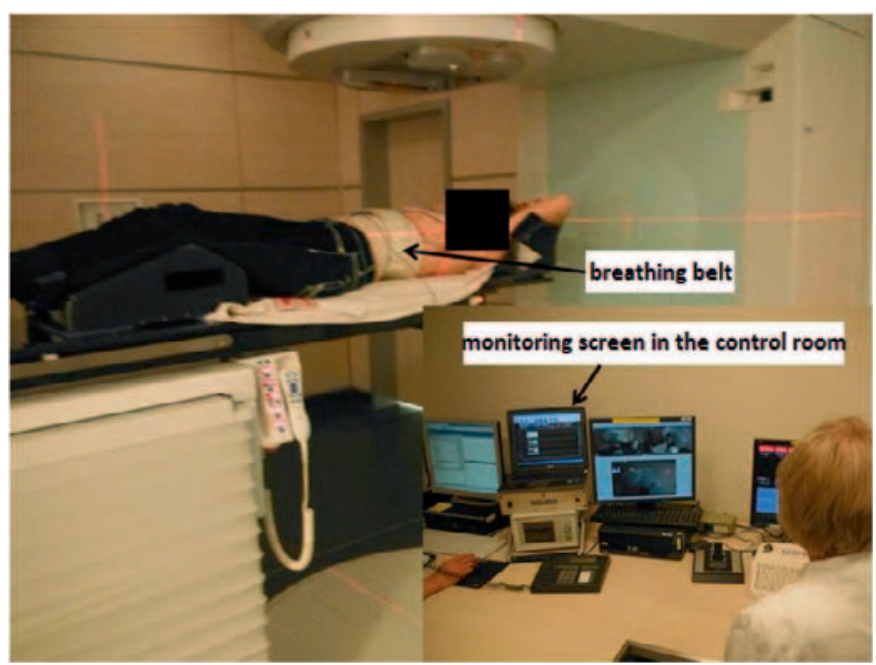

Fig. 2. Irradiation with deep inspiration and respiratory arrest. The patient wears a belt, by which the breathing is detected. In the control room, the technician can follow the respiratory excursions on the monitor. Irradiation is performed in a defined respiratory position (after command: 'Please inhale deeply and hold the breath') and may be interrupted. Depending on the duration of irradiation (usually $20-30 \mathrm{~s}$ per irradiation field) 1 or 2 respiratory cycles per treatment field are required.

deviation (SD) 2.2 Gy), using a widespread modern computed tomography (CT)-based 3-dimensional radiotherapy planning [23]. The irradiation dose to the heart is low even when the planning target volume (PTV) is enlarged in comparison to routinely standard tangential radiotherapy, as demonstrated by the recently completed European Organisation for Research and Treatment of Cancer (EORTC) study 22922. The study showed an advantage of additional irradiation of the parasternal lymph nodes. No increased cardiac mortality was seen although, from experience, the highest cardiac doses result from the irradiation of the parasternal lymph nodes [24]. Even in the combination of radiation therapy and chemotherapy with cardiotoxic drugs (e.g. anthracyclines, trastuzumab), no increased risk due to radiotherapy was observed [2527]. The cardiac risk of radiotherapy in breast cancer is certainly less than the risks of several drug therapies. However, up to now, it still remains unclear if late effects after combination of both therapies can become manifest in old age with decreasing compensation ability of the heart. Finally, this is not a specific radiotherapeutic problem [27].

\section{New Techniques for Cardiac Protection}

At present, the deep inspiration breath hold technique (DIBH) is increasingly used more or less routinely [28-30]. In deep inspiration, the heart sinks down and the distance to the chest wall increases. First dosimetric studies on individual patients showed a significant reduction in heart and lung dose (figs. 1 and 2). It has to be clarified whether the unique dosimetric advantage is clinically relevant or not, so that the use of this method is currently not mandatory. Irradiation in prone position is another promising treat- 
ment option. Several publications are in favor of replacing the supine standard treatment by the prone position for whole-breast irradiation, especially in patients with large breasts [31-33]. Recently, Mulliez et al. [31] reported a phase III randomized trial in this context, in which skin desquamation, dermatitis and edema were significantly reduced. Moreover, also the dose to the ipsilateral lung and the left anterior descending coronary artery were significantly reduced. Comparing the prone and supine treatment positions in 400 patients, Formenteri et al. [33] evaluated the infield volumes of the heart receiving the full dose as a surrogate for normal-tissue exposure. They described a considerable anatomical variability of the volume range, but were also able to show a significantly lower mean dose to the heart in the prone position. Another way to reduce heart toxicity in radiotherapy of breast cancer is the use of the evolving techniques in accelerated partial breast irradiation (APBI), which exclusively targets only the lumpectomy site plus some margin. The rationale for APBI is based on the fact that $75-85 \%$ of the local recurrences after breast cancer surgery occurred at or near the original lumpectomy site [34]. Current techniques in the delivery of APBI are intraoperative radiotherapy (IORT), multi-interstitial brachytherapy, intracavitary brachytherapy, and also external beam radiotherapy. The available data on APBI suggests acceptable local control and survival in selected patients with low-risk breast cancer. However, APBI is not applicable in patients with high-risk features as evidence from modern trials with long-term follow-up is still missing in this context [35]. There are also a rising number of patients undergoing oncoplastic surgery, for which the role of APBI is also not yet defined. Further on, the techniques of APBI are not widely available and only delivered in specialized radiooncology departments. The German S3 guidelines from 2012 [36] state that APBI as sole intra- or postoperative radiation treatment does not represent the standard of care at that time. Outside of clinical trials, APBI should only be delivered to patients for whom whole-breast radiotherapy is not applicable.

\section{Conclusion for Daily Practice}

A significant cardiotoxicity in modern adjuvant radiotherapy for breast cancer has not been observed with the currently used modern radiation techniques, neither in simple nor in complex planning target volumes. This relates also to the combination of irradiation with chemotherapy and immunotherapy. Radiotherapy is now safer than in the past, but a longer follow-up is needed in order to verify the exact late effects.

\section{Disclosure Statement}

All authors declare no conflict of interests.

\section{References}

1 Cuzick J, Stewart H, Peto R, Baum M, Fisher B, Host H, Lythgoe JP, Ribeiro G, Scheurlen H, Wallgren A: Overview of randomized trials of postoperative adjuvant radiotherapy in breast cancer. Cancer Treat Rep 1987;71:15-29.

2 Henson KE, McGale P, Taylor C, Darby SC: Radiationrelated mortality from heart disease and lung cancer more than 20 years after radiotherapy for breast cancer. Br J Cancer 2013;108:179-182.

3 Clarke M, Collins R, Darby S, Davies C, Elphinstone P, Evans E, Godwin J, Gray R, Hicks C, James S, MacKinnon E, McGale P, McHugh T, Peto R, Taylor C, Wang Y; Early Breast Cancer Trialists' Collaborative Group (EBCTCG): Effects of radiotherapy and of differences in the extent of surgery for early breast cancer on local recurrence and 15-year survival: an overview of the randomised trials. Lancet 2005;366:2087-2106.

4 Early Breast Cancer Trialists' Collaborative Group (EBCTCG), Darby S, McGale P, Correa C, Taylor C, Arriagada R, Clarke M, Cutter D, Davies C, Ewertz M, Godwin J, Gray R, Pierce L, Whelan T, Wang Y, Peto $\mathrm{R}$ : Effect of radiotherapy after breast-conserving surgery on 10-year recurrence and 15-year breast cancer death: meta-analysis of individual patient data for 10,801 women in 17 randomised trials. Lancet 2011 ; 378:1707-1716.

5 Sautter-Bihl ML, Sedlmayer F, Budach W, Dunst J, Feyer P, Fietkau R, Fussl C, Haase W, Harms W, Piroth MD, Souchon R, Wenz F, Sauer R; Breast Cancer Expert Panel of the German Society of Radiation Oncology (DEGRO): DEGRO practical guidelines: radiotherapy of breast cancer III - radiotherapy of the lymphatic pathways. Strahlenther Onkol 2014;190:342-351.
6 Darby SC, Ewertz M, McGale P, Bennet AM, BlomGoldman U, Brønnum D, Correa C, Cutter D, Gagliardi G, Gigante B, Jensen MB, Nisbet A, Peto R, Rahimi K, Taylor C, Hall P: Risk of ischemic heart disease in women after radiotherapy for breast cancer. N Engl J Med 2013;368:987-998.

7 Applefeld MM, Slawson RG, Spicer KM, Singleton RT, Wesley MN, Wiernik PH: Long-term cardiovascular evaluation of patients with Hodgkin's disease treated by thoracic mantle radiation therapy. Cancer Treat Rep 1982;66:1003-1013.

8 Mill WB, Baglan RJ, Kurichety P, Prasad S, Lee JY, Moller R: Symptomatic radiation-induced pericarditis in Hodgkin's disease. Int J Radiat Oncol Biol Phys 1984;10:2061-2065.

9 Friedrich SA, Unverdorben M, Kunkel B, Dunst J: [The late cardiac sequelae after mantle-field irradiation. The results in Erlangen's patient caseload]. Strahlenther Onkol 1996;172:19-24.

10 Aleman BM, van den Belt-Dusebout AW, Klokman WJ, Van't Veer MB, Bartelink H, van Leeuwen FE: Long-term cause-specific mortality of patients treated for Hodgkin's disease. J Clin Oncol 2003;21:3431-3439.

11 Hancock SL, Tucker MA, Hoppe RT: Factors affecting late mortality from heart disease after treatment of Hodgkin's disease. JAMA 1993;270:1949-1955.

12 Eriksson F, Gagliardi G, Liedberg A, Lax I, Lee C, Levitt S, Lind B, Rutqvist LE: Long-term cardiac mortality following radiation therapy for Hodgkin's disease: analysis with the relative seriality model. Radiother Oncol 2000;55:153-162.
3 Gagliardi G, Lax I, Ottolenghi A, Rutqvist LE: Longterm cardiac mortality after radiotherapy of breast cancer - application of the relative seriality model. $\mathrm{Br} \mathrm{J}$ Radiol 1996;69:839-846.

14 Schultz-Hector S, Trott KR: Radiation-induced cardiovascular diseases: is the epidemiologic evidence compatible with the radiobiologic data? Int J Radiat Oncol Biol Phys 2007;67:10-18.

15 Sardaro A, Petruzzelli MF, D’Errico MP, Grimaldi L, Pili G, Portaluri M: Radiation-induced cardiac damage in early left breast cancer patients: risk factors, biological mechanisms, radiobiology, and dosimetric constraints. Radiother Oncol 2012;103:133-142.

16 Schultz-Hector S, Böhm M, Blöchel A, Dominiak P, Erdmann E, Müller-Schauenburg W, Weber A: Radiation-induced heart disease: morphology, changes in catecholamine synthesis and content, beta-adrenoceptor density, and hemodynamic function in an experimental model. Radiat Res 1992;129:281-289.

17 Lind PA, Pagnanelli R, Marks LB, Borges-Neto S, Hu C, Zhou SM, Light K, Hardenbergh PH: Myocardial perfusion changes in patients irradiated for left-sided breast cancer and correlation with coronary artery distribution. Int J Radiat Oncol Biol Phys 2003;55:914920.

18 Lorenzen EL, Taylor CW, Maraldo M, Nielsen MH, Offersen BV, Andersen MR, O'Dwyer D, Larsen L, Duxbury S, Jhitta B, Darby SC, Ewertz M, Brink C: Inter-observer variation in delineation of the heart and left anterior descending coronary artery in radiotherapy for breast cancer: a multi-centre study from Denmark and the UK. Radiother Oncol 2013;108:254-258. 
19 Wei X, Liu HH, Tucker SL, Wang S, Mohan R, Cox JD, Komaki R, Liao Z: Risk factors for pericardial effusion in inoperable esophageal cancer patients treated with definitive chemoradiation therapy. Int J Radiat Oncol Biol Phys 2008;70:707-714.

20 Machann W, Beer M, Breunig M, Störk S, Angermann C, Seufert I, Schwab F, Kölbl O, Flentje M, Vordermark D: Cardiac magnetic resonance imaging findings in 20-year survivors of mediastinal radiotherapy for Hodgkin's disease. Int J Radiat Oncol Biol Phys 2011; 79:1117-1123.

21 Taylor CW, Nisbet A, McGale P, Goldman U, Darby SC, Hall P, Gagliardi G: Cardiac doses from Swedish breast cancer radiotherapy since the 1950s. Radiother Oncol 2009;90:127-135.

22 Dellas K, Vonthein R, Zimmer J, Dinges S, Boicev AD, Andreas P, Fischer D, Winkler C, Ziegler A, Dunst J; ARO Study Group: Hypofractionation with simultaneous integrated boost for early breast cancer: results of the German multicenter phase II trial (ARO-2010-01). Strahlenther Onkol 2014;190:646-653.

23 Nitsche M, Temme N, Förster M, Reible M, Hermann RM: The effect of standard tangential radiotherapy vs. defined radiotherapy on early breast cancer treatment without axillary lymph node dissection: a comparative study. Strahlenther Onkol 2014;190:715-721.

24 Poortmans P, Struikmans H, Kirkove C, Budach V, Maingon P, Valli MC, Collette S, Fourquet A, Bartelink $\mathrm{H}$, Van den Bogaert W: Irradiation of the internal mammary and medial supraclavicular lymph nodes in stage I to III breast cancer: 10 years results of the EORTC radiation oncology and breast cancer groups phase III trial 22922/10925. Eur J Cancer 2013;49(suppl 3).
25 Shaffer R, Tyldesley S, Rolles M, Chia S, Mohamed I: Acute cardiotoxicity with concurrent trastuzumab and radiotherapy including internal mammary chain nodes: a retrospective single-institution study. Radiother Oncol 2009;90:122-126.

26 Petersen C, Würschmidt F: Late toxicity of radiotherapy: a problem or a challenge for the radiation oncologist? Breast Care (Basel) 2011;6:369-374.

27 Schlitt A, Jordan K, Vordermark D, Schwamborn JR, Langer T, Thomssen C: Cardiotoxicity and oncological treatments. Dtsch Arztebl Int 2014;111:161-168.

28 Pedersen AN, Korreman S, Nyström H, Specht L: Breathing adapted radiotherapy of breast cancer: reduction of cardiac and pulmonary doses using voluntary inspiration breath-hold. Radiother Oncol 2004;72:53-60.

29 Hjelstuen MH, Mjaaland I, Vikström J, Dybvik KI: Radiation during deep inspiration allows loco-regional treatment of left breast and axillary-, supraclavicularand internal mammary lymph nodes without compromising target coverage or dose restrictions to organs at risk. Acta Oncol 2012;51:333-344

30 Nissen HD, Appelt AL: Improved heart, lung and target dose with deep inspiration breath hold in a large clinical series of breast cancer patients. Radiother Oncol 2013;106:28-32.

31 Mulliez T, Veldeman L, van Greveling A, Speleers B, Sadeghi S, Berwouts D, Decoster F, Vercauteren T, De Gersem W, Van den Broecke R, De Neve W: Hypofractionated whole breast irradiation for patients with large breasts: a randomized trial comparing prone and supine positions. Radiother Oncol 2013;108:203-208.
32 Lymberis SC, deWyngaert JK, Parhar P, Chhabra AM Fenton-Kerimian M, Chang J, Hochman T, Guth A, Roses D, Goldberg JD, Formenti SC: Prospective assessment of optimal individual position (prone versus supine) for breast radiotherapy: volumetric and dosimetric correlations in 100 patients. Int J Radiat Oncol Biol Phys 2012;84:902-909.

33 Formenti SC, DeWyngaert JK, Jozsef G, Goldberg JD: Prone vs supine positioning for breast cancer radiotherapy. JAMA 2012;308:861-863.

34 Veronesi U, Cascinelli N, Mariani L, Greco M, Saccozzi R, Luini A, Aguilar M, Marubini E: Twenty-year follow-up of a randomized study comparing breastconserving surgery with radical mastectomy for early breast cancer. N Engl J Med 2002;347:1227-1232.

35 Barry M, Ho A, Morrow M: The evolving role of partial breast irradiation in early-stage breast cancer. Ann Surg Oncol 2013;20:2534-2540.

36 Interdisziplinäre S3-Leitlinie für die Diagnostik, Therapie und Nachsorge des Mammakarzinoms, Langversion 3.0, Aktualisierung 2012, AWMF-Register-Nummer: $032-045 \mathrm{OL}$, www.awmf.org. 